\title{
MEGAEVENTOS ESPORTIVOS E EDUCAÇÃO FÍSICA: ESTUDO NO FACEBOOK COM PROFESSORES EM FORMAÇÃO INICIAL ${ }^{53}$
}

\author{
Silvan Menezes dos Santos \\ Universidade Federal do Paraná, Curitiba, Paraná, Brasil \\ Giovani de Lorenzi Pires \\ Universidade Federal de Santa Catarina, Florianópolis, Santa Catarina, Brasil
}

\begin{abstract}
Resumo
No momento esportivo de realização de grandes eventos, a preocupação com suas implicações à cultura esportiva do País tornou-se pauta importante para estudos acadêmicos. O objetivo dessa pesquisa foi compreender como professores de Educação Física em formação inicial interagem com o discurso midiático-esportivo sobre megaeventos, no âmbito da convergência digital dos meios. Foi um estudo observacional-descritivo, com cinco estudantes da licenciatura em Educação Física da UFSC. A investigação aconteceu em dois cenários: 1) online, no Facebook; e 2) offline, com questionários e entrevista. Os sujeitos apresentaram uma perspectiva crítica sobre a temática, mas demonstraram dificuldade em visualizá-la, aproximando as dimensões teóricas e práticas da área.
\end{abstract}

Palavras-chave: Esporte. Educação Física. Cultura. Rede Social.

\section{Introdução}

Os megaeventos esportivos tornaram-se realidade concreta para o povo brasileiro e chegaram carregados de um discurso promissor de legado social, cultural, de infraestrutura urbana e, principalmente, esportivo. São promessas de que o País desfrutará de uma herança deixada pelas instituições burocráticas do esporte (COI, FIFA, COB e CBF) organizadoras e promotoras dos eventos, juntamente com os três níveis de governo: federal, estadual e municipal (este último das cidades que irão sediar jogos da Copa do Mundo de Futebol e da cidade do Rio de Janeiro, no caso dos Jogos Olímpicos). Um discurso permeado por interesses políticos e econômicos, pois envolve cifras exorbitantes de recursos públicos e de patrocinadores oficiais, o que acaba englobando também interesses diretos da indústria midiática, por ser detentora dos direitos de transmissão das competições e um importante espaço de divulgação publicitária das marcas envolvidas no negócio.

Sob esse prisma de reciprocidade econômica entre o Esporte e a Mídia (BETTI, 1998), coloca-se em pauta aspectos que passam a constituir a cultura esportiva no País ante a década do

${ }^{53}$ Esta pesquisa teve apoio financeiro da Coordenação de Aperfeiçoamento de Pessoal de Nível Superior — CAPES, sob a forma de bolsa de estudos de pós-graduação. 
esporte, a qual estamos vivendo desde o Pan Rio-2007, passando pela Copa do Mundo FIFA-2014, até às Olimpíadas Rio-2016.

Nessa perspectiva, entendemos cultura esportiva como:

o conjunto de ações, valores e compreensões que representam o modo predominante de ser/estar na sociedade globalizada, em relação ao seu âmbito esportivo, cujos significados são simbolicamente incorporados através, principalmente, da mediação feita pela indústria da comunicação de massa (PIRES, 2002, p. 42).

A partir desse entendimento, e por conta da preocupação com o que esse entrelaçamento entre esporte e mídia pode trazer de impactos e implicações para a cultura esportiva no País, consideramos neste trabalho a corrente latinoamericana da Sociologia da Comunicação, representada pela teoria das mediações culturais de Jesús Martín-Barbero, na qual se preconiza que há dimensões mediadoras da relação entre elementos da Cultura e da Comunicação (MARTÍNBARBERO, 2009). No caso específico deste estudo, direcionamos a interpretação do entrelaçamento dos dois, na constituição dos significados do Esporte no contexto dos megaeventos esportivos no País.

Não diferente, sem se isentar, a área da Educação Física, que tradicionalmente lida com o Esporte e as suas manifestações na Sociedade, vem se preocupando com os impactos desse "tsunami esportivo" (MASCARENHAS, 2012) no processo de desenvolvimento do esporte no Brasil, nas suas diferentes perspectivas: no 'de alto rendimento', no 'educacional' e no 'como lazer'.

No âmbito do esporte educacional, vale retomar aqui que a Educação Física brasileira passou, nas décadas de 1980 e 1990, por um processo de (auto)crítica, sobretudo em relação à esportivização da Educação Física escolar, o que provocou alguns mal-entendidos na área e desnorteou principalmente a sua prática pedagógica. A intervenção educacional no esporte, que até então tinha convicção do entendimento da Educação Física na escola como base da pirâmide esportiva, depois de alguma resistência aceitou o discurso das concepções críticas, mas não o compreendendo suficientemente a ponto de ressignificar a sua ação didático-pedagógica, portanto, sem conseguir materializar as novas orientações educacionais que surgiam.

A ruptura teórica e metodológica conduzida pelas concepções críticas passou e ainda passa por um processo de crítica à crítica, que a coloca entre o "não mais" aquele modelo esportivo de anteriormente, mas também o "ainda não" do que realmente deve-se ou pretende-se fazer com a prática pedagógica da Educação Física escolar (GONZÁLEZ; FENSTERSEIFER, 2009; 2010).

Nesse sentido, com a "orfandade" pela qual vem passando a Educação Física escolar nos últimos anos (BRACHT, 2001) ${ }^{54}$, a comunidade científica da área, sobretudo a das Ciências do Esporte, tem demonstrado preocupação com a chegada dos megaeventos esportivos no Brasil. Há

\footnotetext{
${ }^{54}$ No texto, Valter Bracht diz que a Educação Física estaria em um orfanato pelo fato de a sua legitimidade no espaço escolar ter se constituído, historicamente, através dos paradigmas biomédicos, os quais preconizavam a prática de atividade física e de esporte como meios de se alcançar a saúde e o bem-estar social, mas que, agora, tais paradigmas demonstram um certo esgotamento no âmbito da Educação Física escolar.
} 
uma tensão sobre os possíveis impactos que essa década esportiva no País pode acarretar para a prática pedagógica da Educação Física na escola (BRACHT; ALMEIDA, 2013). Mais ainda, o campo tem pensado de que maneira a política esportiva desenvolvida por conta da Copa e das Olimpíadas valorizaria a Educação Física no projeto educacional da Nação (MASCARENHAS, 2012). Também se pergunta se esse momento poderia desencadear um processo de re-esportivização da Educação Física escolar.

Em paralelo à problemática da relação e das implicações dos megaeventos ao contexto da Educação Física, principalmente nessa perspectiva sociocultural do esporte da qual falamos até aqui, consideramos também o contemporâneo processo de transformação comunicacional, que se convencionou chamar de "convergência digital". Para a formação de uma "cultura da convergência", segundo Jenkins (2009), é necessário, de início, e para que seja compreendida, ter ciência do momento de entrelaçamento entre velhas e novas mídias, do cruzamento entre a indústria midiática e a mídia alternativa e das redes sociais, além das novas interações de poder entre o produtor e o consumidor do discurso midiático. Uma nova cultura dos meios que, para o pesquisador norte-americano, envolve mais que uma simples fusão tecnológica de suportes, é uma transformação cultural que demanda participação social e trabalho intelectual coletivo.

Portanto, a relação do esporte com a mídia tem, nesse momento, dois elementos que modificam ou, ao menos, começam a criar um novo espectro entre esses dois objetos: a realização dos megaeventos esportivos no Brasil, e a cobertura midiática do esporte em tempos de convergência digital.

Assim, no âmbito da convergência digital, cabe questionar: 'de que maneira as mediações culturais se expressam na interação de professores de Educação Física em formação inicial com conteúdos relativos ao discurso midiático-esportivo sobre megaeventos no Brasil?'.

De acordo com o quadro descrito, o propósito desta pesquisa esteve ligado à construção da cultura esportiva do País, no centro deste "novo" contexto do esporte nacional e do discurso midiático sobre o fenômeno. Mais ainda, nos interessou entender como a Educação Física, através de seus professores em formação inicial - principais mediadores e formadores da cultura esportiva no interior da escola - se inserem e intervém neste contexto esportivo atual. Assim, o objetivo geral desta pesquisa foi identificar como professores de Educação Física em formação inicial interagem com o discurso midiático-esportivo, no âmbito da convergência digital dos meios.

\section{Percurso e estratégias metodológicas de investigação}

Mediante o estágio paradigmático da comunicação social de convergência dos meios, onde se pode consumir, produzir e compartilhar informações diversas, para entender como os sujeitos lidavam com o discurso midiático-esportivo na conformação da própria cultura esportiva, relacionando os megaeventos esportivos com a Educação Física, esta pesquisa foi desenvolvida como um 'estudo observacional-descritivo com uma abordagem qualitativa dos dados produzidos para análise'.

Para compreender as práticas sociais e culturais dos sujeitos, a pesquisa foi desenvolvida em duas etapas: a primeira etapa foi a investigação online e a segunda, offline. É válido deixar claro que foram momentos investigativos e técnicas metodológicas complementares, que não assumiram a compreensão dicotômica entre contextos virtuais e reais, ou online e offline. 
No primeiro momento, denominado 'cenário online' de investigação, foram acompanhadas as páginas pessoais de cinco interlocutores, que se disponibilizaram a participar da pesquisa. Todos eles, professores em formação inicial do curso de licenciatura em Educação Física da Universidade Federal de Santa Catarina, os quais aceitaram contribuir com o estudo de maneira voluntária, após serem selecionados a partir de convite enviado para as turmas de graduação do Centro de Desportos da referida universidade. O principal critério de inclusão foi que os sujeitos tivessem e fizessem uso de conta na rede social Facebook e autorizassem o seu acompanhamento.

No período de 12 de junho a 31 de julho de 2013, ou seja, por 50 dias seguidos, foram recolhidas todas as informações disponíveis no perfil do Facebook dos sujeitos da pesquisa. Como corpus de análise, foram salvos todos os tipos de interação realizados por eles na plataforma (postagens, compartilhamentos, comentários), que tivesse conteúdo relacionado ao objeto de estudo (Megaeventos Esportivos, Copa das Confederações, Esporte e Educação Física).

A delimitação do período de acompanhamento do perfil dos sujeitos na rede social foi definida de acordo com as datas de realização da Copa das Confederações no Brasil (15 a 30 de junho). O intuito deste recorte temporal foi de acompanhar a discussão dos sujeitos sobre o megaevento esportivo durante e nos 30 dias após a realização dele, para ter uma visão da repercussão momentânea e posterior do então objeto estudado.

Concomitante a esse primeiro cenário, desenvolvemos o 'cenário offline' do estudo, como estratégia de aproximação do pesquisador com os sujeitos da pesquisa e também como abordagem complementar e problematizadora da observação inicial dos sujeitos no ambiente online. Nesse momento, foram utilizadas duas técnicas metodológicas para a produção de dados.

O primeiro instrumento foi um 'questionário misto', com perguntas fechadas e abertas, o qual foi aplicado presencialmente, antes do início da observação e do acompanhamento dos perfis no Facebook. Após o término do cenário online, foi realizada uma 'entrevista coletiva semiestruturada', a partir de apontamentos suscitados pelo cenário online. A técnica de entrevista com os sujeitos compôs a pesquisa como uma estratégia de aprofundamento dos dados colhidos na investigação até então.

Para a organização e interpretação dos dados foi utilizado o método de Análise de Conteúdo (BARDIN, 2009) e "Análise de Conteúdo temática", uma variação proposta por Minayo (2006). Conforme Minayo, na análise de conteúdo temática as categorias podem ser teóricas ou empíricas. Neste caso, foi elencado o tema relacionado ao objeto de estudo, advindo, basicamente, do quadro teórico de referência: megaeventos esportivos. A partir disso, de acordo com as orientações metodológicas para os procedimentos de leitura, organização, análise e interpretação dos dados, foram criadas unidades de registro com os achados da pesquisa, que englobaram os dados dos questionários, das interações dos sujeitos no Facebook e as informações recolhidas durante a entrevista realizada no fim dos procedimentos de investigação. Essas unidades de registro foram organizadas e deram origem às subcategorias empíricas da categoria temática referida.

$\mathrm{Na}$ sequência, trazemos apenas alguns exemplos dos dados colhidos durante a pesquisa para caracterizar o modo como eles foram organizados, analisados e discutidos, de acordo com a base teórica definida para este trabalho. 


\section{ANÁLISE E DISCUSSÃO DOS DADOS - 'Megaeventos esportivos'... entre o sim, o não, ou... o sim e o não}

As contradições e os conflitos de posições, favoráveis e contrárias, em torno da realização dos megaeventos, vem deixando algumas lacunas e dúvidas para aqueles que compõem a comunidade acadêmico-científica da Educação Física e de áreas afins. Mesmo entendendo que na maioria dos casos a preocupação não é exatamente esta, já que a realização da Copa do Mundo e dos Jogos Olímpicos no Brasil é um fato consumado, são inúmeros os fatores apontados nos debates teóricos da academia, que acabam por não deixar claro a postura a ser tomada acerca dos acontecimentos dessa "década esportiva" no País. Desse modo, o que foi possível identificar, a partir dos interlocutores do estudo, é que com relação à temática dos megaeventos esportivos, é difícil se posicionar, ficando assim entre o 'sim' e o 'não' - ou, mais precisamente, 'o sim e o não' (!).

Primeiro, foram apresentadas questões críticas concernentes à necessidade de realização dos megaeventos com o contraponto da identificação brasileira com o esporte, especificamente com o futebol. Os interlocutores também expressaram uma posição questionadora acerca dos legados, principalmente com propriedade sobre a experiência já vivida com o Pan Rio-2007. Demonstraram com isso fazer uma leitura ampliada no que se refere ao contexto e aos bastidores que cercam a cobertura midiática e o espetáculo esportivo. Isto posto, indicaram uma perspectiva bem definida sobre o papel a ser exercido pela Educação Física Escolar no trato com o conteúdo esporte e, no caso, com o tema dos megaeventos.

\section{IDENTIDADE VS. NECESSIDADE: "Não precisamos dos megaeventos, mas os queremos pela nossa Seleção"}

O dilema interpretativo da realização dos megaeventos no Brasil foi também reforçado na fala dos interlocutores da pesquisa. A posição apresentada por eles esteve, em boa parte das afirmações e das interações na rede social, ligada a uma perspectiva crítica, de defesa dos direitos dos cidadãos e de respeito à utilização dos recursos públicos. Porém, em alguns casos, também deram indícios que se mantém vinculados a símbolos que constituem a tradição da cultura esportiva do País e que representam, para eles, a necessidade de realização de um evento como a Copa do Mundo de Futebol no território brasileiro. Por exemplo, a relação identitária com o futebol através da Seleção Brasileira e dos clubes esportivos da modalidade (cf. Figura 1, abaixo, em que o jogador Paulinho ainda é associado ao Corinthians, mesmo não sendo jogador deste Clube). 


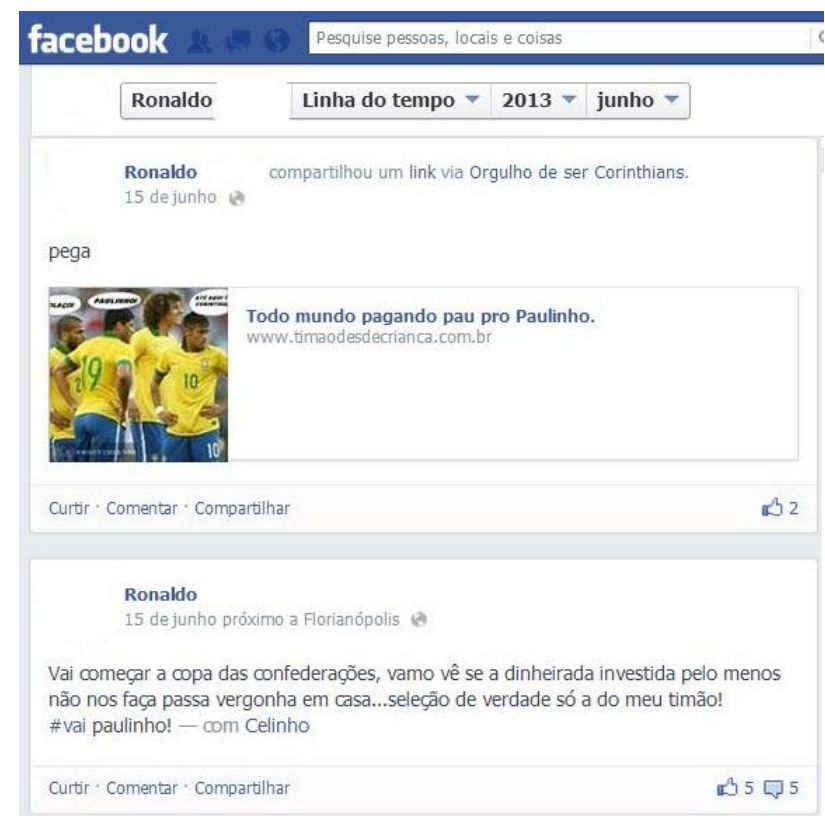

\section{Figura 1 - Compartilhamento e Postagem em 15 jun. 2013: dia da Abertura da Copa das Confederações e estreia da Seleção Brasileira na competição.}

Nesse sentido, Bitencourt (2009, p. 177) defende o argumento de que "só há identidade na relação. É preciso um outro para que [se] possa estabelecer a identidade. Só há identidade na alteridade". Assim, as postagens na data de início da Copa das Confederações, antes e depois do jogo de abertura da Seleção Brasileira de Futebol, sugerem um exemplo de como se pode identificar alguém a algo ou a algum grupo social. Nesse caso, as relações identitárias do sujeito com o futebol estabelecem-se entre o escrete canarinho e o Sport Club Corinthians (clube de futebol da cidade de São Paulo).

O primeiro, quando identificou-se como pertencente à "comunidade imaginada" (ANDERSON, 1991 apud BITENCOURT, 2009) dos brasileiros, representados pelo time selecionado, o qual não pode "passar vergonha" jogando no território nacional, depois de ter gastado tanto dinheiro na realização do evento. E o segundo, quando se refere ao clube do coração como "meu timão", que é uma forma popular e carinhosa de os torcedores chamarem o Corinthians, associando e comparando-o à seleção de futebol. Além disso, o compartilhamento que o interlocutor da pesquisa faz do conteúdo advindo da página 'Orgulho de ser Corinthians' traz um link para uma imagem onde aparecem os jogadores da seleção exaltando a atuação do ex-jogador do Clube (Paulinho) na primeira partida da Copa das Confederações.

Em meio a uma sutil crítica aos gastos excessivos para a construção dos estádios da Copa, o sentimento comunitário de pertencimento expressado pelo sujeito na postagem (Figura 1) pode ser entendido no que Bitencourt (2009, p. 181) sugere: "é na seleção brasileira de futebol que nosso pensamento sobre nós mesmos é levado ao extremo. É esse o espaço no qual nossa identidade vai ser debatida, inventada e construída. A seleção é a representação de nossas representações sobre nós mesmos". O autor ainda complementa afirmando que é "nesse jogo [...] que os brasileiros pensam- 
se como povo, como 'raça' (mas pensam também sua economia, sua política) e traçam o seu destino pela bola" (BITENCOURT, 2009, p. 186).

É sob esse prisma identificador do nacionalismo brasileiro com o futebol, em paralelo com o fanatismo e a paixão pelos clubes, que, assim como os outros, um dos interlocutores se colocou diante do dilema em assumir uma postura frente à realização dos megaeventos, em específico da Copa no Brasil. A lástima de estar ciente dos imbróglios existentes por trás dos panos, desviando um olhar crítico para o fenômeno, com o contrapeso do sentimento de brasilidade através do futebol, do clubismo e da Seleção Brasileira.

Esse exemplo trazido pode representar a mediação cultural da ritualidade, conforme apontada por Martín-Barbero (2009), na qual os rituais e os símbolos da cultura dos sujeitos podem conduzir as trajetórias de leitura deles para determinados elementos da comunicação social, no caso o esporte e os megaeventos esportivos, fenômenos da mídia.

\section{COPA DO MUNDO PARA QUEM?: a desilusão quanto aos legados}

Além do simples fato da realização dos megaeventos no Brasil, nós questionamos os futuros professores sobre as expectativas que eles teriam perante o permanente e incisivo discurso dos legados dos megaeventos no Brasil. $\mathrm{O}$ que encontramos foram posições subversivas à tendência discursiva hegemônica e entusiasta, uma indignação sustentada com argumentos sistematizados acerca do problema que permeia, segundo os interlocutores da pesquisa, "a sociedade brasileira e atinge a cidadania nacional".

Amanda: E a impressão que dá nesse tipo de evento, Copa do Mundo, enfim, sobretudo a Copa do Mundo, é que o Estado ele parece um tanto quanto submisso às próprias solicitações da FIFA, enfim, tanto no que diz respeito aos padrões FIFA. Não que o Estado assuma uma postura passiva, mas mais de submissão mesmo. E para a população não vai haver qualquer benefício, então eu acho que esse talvez seja o ponto principal, qual o argumento? Vai ter benefícios para a população? Não! A gente já teve a experiência do Pan de 2007 no Rio, então!

A fala da interlocutora mostra a crítica aos 'não-legados' do Pan Rio-2007, já que muito do que foi prometido para aquele momento não foi cumprido pelas autoridades, como a despoluição da Lagoa Rodrigo de Freitas, da Baía de Guanabara, entre outras promessas.

O exemplo da análise feita pela professora em formação se aproxima do que Souza \& Marchi Júnior (2010) chamam a atenção, o cuidado que se deve ter com a construção dessa cultura de "legado social" a que estamos submetidos no contexto do discurso esportivo oficial do País. Para eles é preciso, antes de acreditarmos nesse discurso, superarmos ou, ao menos, amenizarmos os problemas de desigualdade que a sociedade brasileira carrega como característica do seu projeto de desenvolvimento na modernidade para não corrermos o risco de nos tornarmos os novos "evangelizadores do esporte" (COAKLEY, 2010 apud SOUZA; MARCHI JÚNIOR, 2010).

Visto de outra forma, semelhante aos predecessores desse evangelho, que acreditavam na prática esportiva como objeto de superação e libertação dos sujeitos das zonas de perigo e marginalização social, estaríamos agora remontando a doutrina com a crença de que o legado 
esportivo pode ser um meio de transformação social. Seria, nesse caso, uma reedição do "discurso salvacionista do esporte, o qual, diga-se de passagem, é teoricamente interessante para os grupos dominantes e, em contrapartida, com efeitos práticos quase que nulos e inatingíveis para os grupos dominados" (SOUZA; MARCHI JÚNIOR, 2010, p. 250-251).

A partir do exemplo da fala da interlocutora, podemos visualizar a mediação cultural que a experiência social vivida com o Pan 2007 proporcionou para a formação do olhar desvelado de ilusão quanto ao discurso dos legados dos megaeventos esportivos no País. Exemplo pelo qual podemos caracterizar o papel da mediação da socialidade (MARTÍN-BARBERO, 2009), quando fatos ou relações sociais interferem nos significados atribuídos pelos sujeitos a determinados fenômenos ou discursos da mídia.

\section{O ESPETÁCULO ESPORTIVO: belo jogo de futebol como "política de pão e circo"}

Em paralelo às análises apresentadas durante os questionamentos realizados nas entrevistas e nas interações realizadas na rede social, os sujeitos da pesquisa mostraram-se ligados, de algumas maneiras, à competição da Copa das Confederações. Tanto no que diz respeito aos elementos futebolísticos propriamente ditos, pois eles fizeram postagens sobre aspectos táticos e técnicos da modalidade, e pela representatividade da Seleção Brasileira, quanto em interações nas suas páginas pessoais do Facebook, no que expressaram criticidade ao espetáculo esportivo e às implicações sociais que ele estava causando ao País. É possível visualizar os exemplos nas Figuras 2,3 e 4 abaixo.

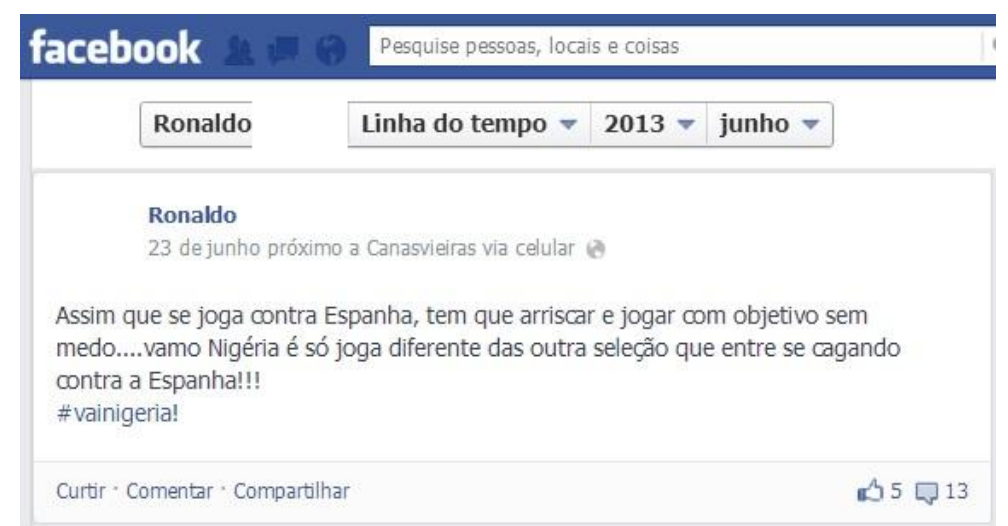

Figura 2 - Postagem de Ronaldo, em 23 jun. 2013. 


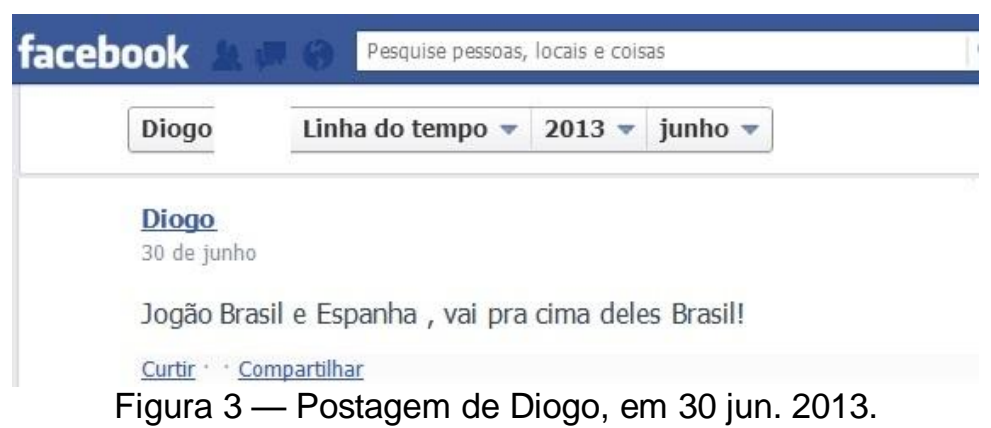

Figura 3 - Postagem de Diogo, em 30 jun. 2013.

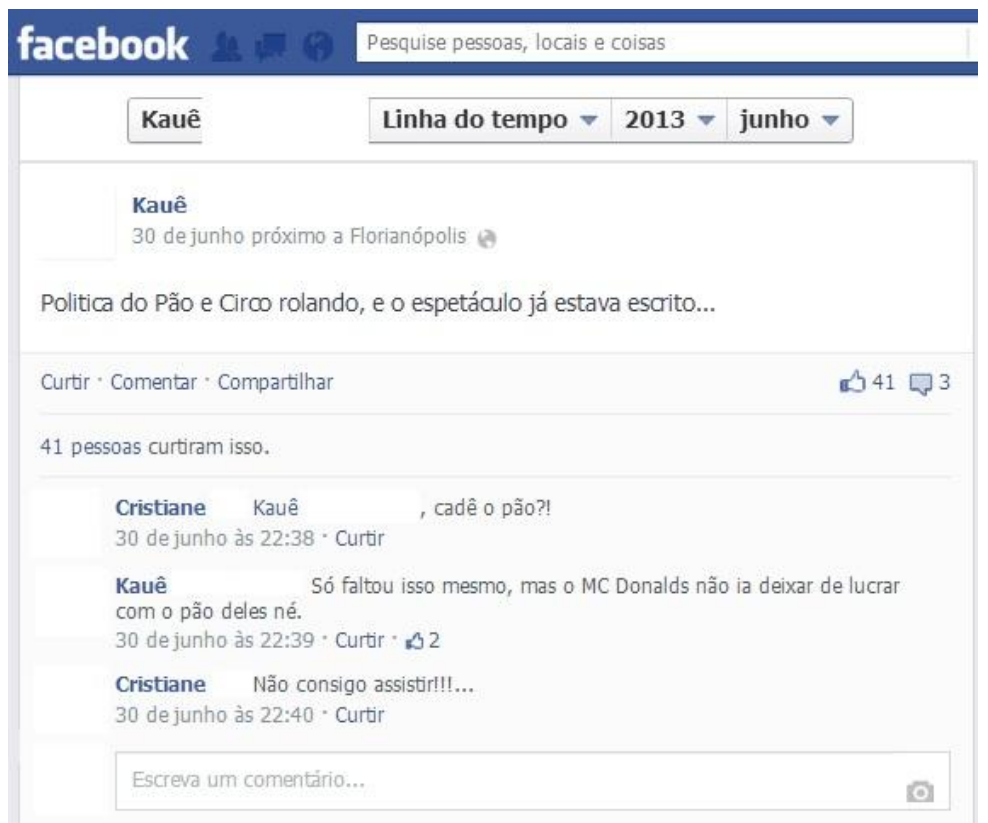

Figura 4 - Postagem de Kauê, em 30 jun. 2013.

Na postagem de Kauê, e no diálogo que ele estabelece com a sua amiga da rede (Figura 4), ele menciona a política do "pão e circo" para fazer uma leitura do jogo da final da Copa das Confederações, que aconteceu no dia 30 de junho, entre as seleções, brasileira e espanhola no Maracanã. Assim como aconteciam nas arenas da Roma Antiga, o estádio estava lotado, com cerca de 80 mil pessoas, que, de acordo com a associação pretendida por Kauê, estavam ali envolvidas pelo entretenimento proporcionado pelo Estado para controlar as massas, fazendo-as sentir o pertencimento à Nação e evitando que elas se rebelem contra o modelo de governo e as mazelas sociais, da mesma forma que em outros tempos. Além disso, ele ousa afirmar, ainda, que o "espetáculo já estava escrito", colocando em dúvida a imprevisibilidade do resultado vitorioso de 3 a 0 da Seleção Brasileira sobre os atuais campeões mundiais.

Portanto, as postagens realizadas pelos sujeitos da pesquisa (Figuras 2, 3 e 4) demonstram como o sentimento nacionalista ligado ao futebol acaba sendo uma premissa do brasileiro 
aficionado na modalidade. Uma construção sociocultural que contou com a colaboração do telespetáculo esportivo (BETTI, 1998) e que, não por acaso, em alguns momentos, os sujeitos reproduzem a discursividade da falação esportiva (ECO, 1984).

Porém, há também indicativos de que a paixão pelo esporte não os impede de desviar um olhar crítico em relação ao modelo espetacular em que se estruturam os megaeventos esportivos, fazendo análises, inclusive, que se aproximam do que Pires (2002) argumentou sobre o Esporte, como um dos produtos preferidos da indústria midiática por oferecer, em contrapartida, o show já pronto.

Esses exemplos de interações realizadas pelos sujeitos na rede trazem evidências de como a dimensão institucional do esporte espetáculo, com seus códigos e símbolos próprios, através das suas técnicas discursivas próprias, também pode interferir na significância dada ao fenômeno esportivo por eles. Estariam presentes, então, dois tipos de mediações culturais, conforme modelo do mapa das mediações de Martín-Barbero (2009), a 'institucionalidade' e a 'tecnicidade'.

\title{
O A PRIORI DA EDUCAÇÃO FÍSICA: o pensamento crítico e a necessidade de intervir sem entusiasmo e integração ao espetáculo
}

Diante dessa discussão crítica sobre a temática, composta por movimentos e posições que se contrapõem, em determinados momentos, ao serem questionados sobre a relação e o papel que a Educação Física deveria exercer no trato com o tema dos megaeventos esportivos, nos seus espaços de intervenção social, sobretudo no âmbito escolar, os sujeitos da pesquisa mostraram-se decididos, com uma visão bem definida acerca do que fazer, e também do que não fazer com a situação que se desenhou no País.

\begin{abstract}
Amanda: Eu acho que, no caso pensando a Educação Básica, atuando na Educação Básica, seria o momento ideal para levar isso para os alunos, para as crianças, não como entusiasta disso que tá acontecendo, não tendo uma postura entusiasta disso, mas de crítico, fazer elas pensarem acerca disso porque são eles que são os primeiros cooptados por esse mecanismo do espetáculo, eles são os primeiros.
\end{abstract}

Daniela: Teriam dois lados, o lado da Educação Física voltado para o Bacharelado e para a Licenciatura. [...] na questão da licenciatura, se eu fosse trabalhar, iria com certeza trabalhar esse assunto na escola para começar a ver a opinião dos alunos, ver o que eles entendem por isso e tá trabalhando mesmo, não é, falando a realidade, não dando a resposta pra eles, mas que eles descubram pela percepção deles o que tá acontecendo.

O que se evidencia na fala dos sujeitos é que, apesar dos dilemas apresentados acerca da realização dos megaeventos esportivos no País (conforme já discutido anteriormente no trabalho), eles não negam a importância da tematização do assunto no contexto escolar e ressaltam principalmente a necessidade de aproveitar a efervescência esportiva momentânea para tratá-lo junto aos escolares, que, para Amanda, são um dos principais nichos de mercado atingidos pelo discurso do 'esporte-espetáculo'. 
A afirmação da interlocutora da pesquisa corrobora com o que Bracht \& Almeida (2013, p. 139) compreendem ser o papel a ser exercido pela Educação Física escolar perante os megaeventos esportivos:

Predispor os discentes para esses megaeventos significa ampliar os seus conhecimentos sobre o fenômeno esportivo, e isso envolve tanto o aprendizado dos esportes no sentido de sua prática, suas regras, suas características e lógicas internas, como a compreensão do significado cultural, político e econômico do esporte de uma maneira geral e dos megaeventos em particular.

Nesse sentido, a fala dos interlocutores seguiu a linha de pensamento de que é preciso se pensar uma maneira de conformar o processo de "escolarização do esporte" e evitar riscos de perpetuarmos uma "pseudovalorização da Educação Física escolar" através de políticas públicas que tratam o esporte educacional sob os mesmos moldes do de alto rendimento (BRACHT; ALMEIDA, 2013).

Além disso, os argumentos deles trazem indícios de que já possuem discernimento sobre o papel a ser exercido pelo professor e, no caso, o da Educação Física na Educação Básica. Eles apresentam o entendimento de que a disciplina, como componente curricular que historicamente tratou do Esporte na escola, deve se manter como esse espaço de trabalho dos conteúdos esportivos, mas aproveitá-lo para levar a discussão sobre o tema com uma abordagem crítica, contextualizando os múltiplos elementos e meandros que compõem o fenômeno e os seus marcos representativos, que são os megaeventos.

Eles vão além e apontam o professor de Educação Física não como reprodutor da lógica hegemônica, em que o sistema esportivo se desenvolve oficialmente na sociedade, mas o designam como o mediador das relações de aproximação e estranhamento dos alunos com o fenômeno esportivo no contexto escolar. Percebe-se que em nenhum momento eles levantam a possibilidade de negação à abordagem do esporte na escola, porém ratificam que é preciso se posicionar como um provocador de questões que despertem a curiosidade dos escolares e os levem à descoberta autônoma e esclarecedora do universo esportivo. Portanto, acompanham a compreensão de que a Educação Física deve ser um mediador escolar das relações entre esporte e mídia, assim como indicado em outras investigações (ANTUNES, 2007; LISBOA, 2007; MEZZAROB A, 2008).

\section{Considerações (nunca) finais}

Chegamos ao fim desta investigação, mas consideramos que dificilmente alcançamos o ponto final da discussão de temática tão complexa e tão intrigante para a Educação Física. Assim como tem se observado no campo acadêmico-científico da Educação Física e de áreas afins, os interlocutores da pesquisa mostraram que estão ainda entre o 'sim', o 'não' ou, talvez, 'o-sim-e-onão' da realização dos megaeventos esportivos no País. Por conta disso, eles demonstraram fazer interpretações permeadas por um olhar crítico ao fenômeno, sobretudo no que se refere ao entendimento, ao menos teórico, dos objetivos e obrigações da Educação Física Escolar no trato com o conteúdo em questão.

A partir das interações realizadas na rede social foi possível perceber como a relação deles com o discurso midiático-esportivo sobre os megaeventos é permeado por diferentes mediadores 
culturais. Desde instituições envolvidas no sistema esportivo, como os meios de comunicação de massa, por exemplo, até elementos do contexto social onde estão inseridos, como a identidade brasileira com o futebol e as relações interpessoais de comunicação estabelecida através da rede social, no caso, o Facebook.

Embora ainda em processo de formação inicial, os interlocutores da pesquisa apresentaram, de início, propriedade crítica e capacidade reflexiva de vislumbrar possibilidades de intervenção pedagógica na Educação Física escolar para tratar do tema dos megaeventos esportivos de maneira subversiva, resistindo à tradição do encantamento e da rendição à festa do espetáculo. Muito disso, inclusive, com indicativos de influências formativas das concepções críticas e pedagógicas da área.

Portanto, o que nos parece sensato considerar como reflexões deste investimento investigativo é que, apesar dos avanços e do constante aprofundamento reflexivo que a Educação Física tem realizado nos estudos em Mídia, Esporte e, mais recentemente, Megaeventos Esportivos, ainda há um longo processo de desenvolvimento e amadurecimento para a sua legitimação profissional, sobretudo no projeto educacional de intervenção pedagógica na escola e, antes disso, na formação dos professores. Há de se atentar, principalmente, para que não tenhamos um desequilíbrio na área entre a dimensão teórico-crítica e as dimensões instrumental e produtiva da prática pedagógica.

\title{
MEGA SPORTING EVENTS AND PHYSICAL EDUCATION: A STUDY ON FACEBOOK WITH TEACHERS IN THE INITIAL STAGE OF TRAINING
}

\begin{abstract}
:
At the time of major sporting events, concern about its implications to the sporting culture of the country has become an important agenda for academic studies. The objective of this research was to understand how Physical Education teachers, in the initial stages of training, interact with the media sports speech on mega-events within the digital media convergence. It was an observational and descriptive study, with five licentiateship students in Physical Education at UFSC. The research took place in two scenarios: 1) online on Facebook, and 2) offline, with questionnaires and interviews. The survey subjects showed a critical perspective on the issue but demonstrated difficulty in conceptualizing it, putting together the theoretical and practical dimensions of this field.
\end{abstract}

Keywords: Sports. Physical Education. Culture. Social network.

\section{MEGAEVENTOS DEPORTE Y LA EDUCACIÓN FÍSICA: ESTUDIO EN FACEBOOK CON LOS PROFESORES EN FORMACIÓN INICIAL}

\section{Resumen}

En el momento deportivo de grandes eventos, la preocupación por las consecuencias para su cultura deportiva en el país se ha convertido en una importante agenda para estudios académicos. El objetivo de esta investigación fue entender cómo los profesores de educación física en la formación inicial interactúan con el discurso de los medios de comunicación-deportiva en los mega eventos dentro de la convergencia de los medios digitales. Un estudio observacional descriptivo, con cinco estudiantes de la licenciatura en Educación Física de la UFSC. La investigación se llevó a cabo en dos escenarios: 1) en línea, en Facebook; 2) fuera de línea, con cuestionarios y entrevistas. Los 
sujetos mostraron una perspectiva crítica sobre el tema, pero demostraron dificultades para ver lo que se acerca a las dimensiones teóricas y prácticas de la zona.

Palabras clave: Deporte. Educación Física. Cultura. Red Social.

\section{Referências}

ANTUNES, Scheila Espíndola. O "País do futebol na Copa do Mundo": estudo de recepção ao discurso midiático-esportivo com jovens escolares. Dissertação (Mestrado em Educação Física). Florianópolis: PPGEF/UFSC, 2007.

BARDIN, Laurence. Análise de conteúdo. Lisboa: Edições 70, 2009.

BETTI, Mauro. Janela de vidro: esporte, televisão e educação física. Campinas: Papirus, 1998.

BRACHT, Valter. Saber e fazer pedagógicos: acerca da legitimidade da Educação Física como componente curricular. In: Caparroz, Francisco (org.). Educação Física escolar: política, investigação e intervenção. Vitória: Proteoria, 2001.

; ALMEIDA, Felipe Quintão. Esporte, escola e a tensão que os megaeventos esportivos trazem para a Educação Física Escolar. Em Aberto, Brasília, v. 26, n. 89, p. 131-143, 2013.

BITENCOURT, Fernando. Esboço sobre algumas implicações do futebol e da Copa do Mundo para o Brasil: identidade e ritos de autoridade. Revista Brasileira de Ciencias do Esporte, Campinas, v. 30, n. 3, p. 173-189, maio 2009.

ECO, Umberto. A falação esportiva. In: Nova Fronteira, p. 220-226, 1984.

GONZÁLEZ, Fernando Jaime; FENSTERSEIFER, Paulo Evaldo. Entre o "não mais" e o "ainda não": pensando saídas do não lugar da EF escolar I. Cadernos de Formação RBCE, Florianópolis, p. 9-24, set. 2009.

Entre o "não mais" e o "ainda não": pensando saídas do não lugar da EF escolar II.

Cadernos de Formação RBCE, Florianópolis, p. 10-21, mar. 2010.

JENKINS, Henry. Cultura da convergência. São Paulo: Aleph, 2009.

LISBOA, Mariana Mendonça. Representações do esporte-da-mídia na cultura lúdica de crianças. Dissertação (Mestrado em Educação Física). Florianópolis: PPGEF/UFSC, 2007.

MARTÍN-BARBERO, Jesús. Dos meios às mediações: comunicação, cultura e hegemonia. 6. ed. Rio de Janeiro: Editora UFRJ, 2009.

MASCARENHAS, Fernando. Megaeventos esportivos e Educação Física: alerta de tsunami. Movimento, Porto Alegre, v. 18, n. 1, p. 39-67, jan.-mar. 2012.

MEZZAROBA, Cristiano. Os Jogos Pan-americanos Rio/2007 e o agendamento midiáticoesportivo: um estudo de recepção com escolares. Dissertação (Mestrado em Educação Fìsica). Florianópolis: PPGEF/UFSC, 2008. 
MINAYO, Maria Cecília de Souza. O desafio do conhecimento: pesquisa qualitativa em saúde. 9. ed. São Paulo: Hucitec, 2006.

PIRES, Giovani de Lorenzi. Educação física e o discurso midiático: abordagem críticoemancipatória. Ijuí: Unijuí, 2002. (Coleção Educação Física).

SOUZA, Juliano; MARCHI JUNIOR, Wanderley. Os "legados" dos megaeventos esportivos no Brasil: algumas notas e reflexões. Motrivivência, Florianópolis, ano XXII, n. 34, p. 245-255, jun. 2010.

Recebido em: 12/05/2014

Revisado em: 17/04/2015

Aprovado em: 20/04/2015

Endereço para Correspondência:

Giovani de Lorenzi Pires

delorenzi57@gmail.com

Universidade Federal de Santa Catarina, Centro de Desportos, Departamento de Educação Física Campus Universitário

Trindade

88 040-900 - Florianópolis-SC — Brasil 